\title{
Orai calcium release-activated calcium modulator 1 (ORAl1) plays a role in endoplasmic reticulum stress in bovine mammary epithelial cells challenged with physiological levels of ketone bodies
}

\author{
Bingbing Zhang, ${ }^{1 *} \odot$ Ming Li, ${ }^{2 *} \odot$ Wei Yang, ${ }^{2 *} \odot$ Juan J. Loor, ${ }^{3} \odot$ Shuang Wang, ${ }^{2} \odot$ Yingying Zhao, ${ }^{2} \odot$ \\ Han Guo, ${ }^{2} \odot$ Xinru Ma, ${ }^{2} \odot$ Cheng $\mathrm{Xia}^{2}{ }^{2}$ and Chuang $\mathrm{Xu}^{2} \dagger \odot$ \\ ${ }^{1}$ College of Life Science and Technology, Heilongjiang Bayi Agricultural University, Xinyang Rd. 2, Daqing, 163319, Heilongjiang, China \\ ${ }^{2}$ College of Animal Science and Veterinary Medicine, Heilongjiang Bayi Agricultural University, Xinyang Rd. 2, Daqing, 163319, Heilongjiang, \\ China \\ ${ }^{3}$ Department of Animal Sciences and Division of Nutritional Sciences, University of Illinois, Urbana 61801
}

\section{ABSTRACT}

The Orai calcium release-activated calcium modulator 1 (ORAI1) is a key component of the store-operated $\mathrm{Ca}^{2+}$ entry mechanism regulating cellular $\mathrm{Ca}^{2+}$ balance in nonruminants. Alterations in ORAI1 abundance have been associated with endoplasmic reticulum (ER) stress and changes in lipid metabolism in hepatocytes, an important lipogenic organ in nonruminants. Objectives were to (1) determine abundance of ORAI1 and components of the ER stress response in mammary tissue of ketotic cows, and (2) the potential role of ORAI1 on mammary cell responses to high levels of $\beta$-hydroxybutyrate (BHB). Healthy $(\mathrm{n}=6$, plasma $\mathrm{BHB}<0.60 \mathrm{mmol} / \mathrm{L})$ and clinically ketotic $(\mathrm{n}=6$, plasma $\mathrm{BHB}>2.0 \mathrm{mmol} / \mathrm{L}$ ) Holstein cows (days in milk $=10.13 \pm 1.90)$ were used for mammary gland tissue and blood sample collection. Although milk production $(22.5 \pm 1.26,33 \pm 1.59, \mathrm{~kg}$ of milk/cow per day $)$ and dry matter intake $(19.5 \pm 1.05,21.9 \pm 0.95, \mathrm{~kg} / \mathrm{d})$ were lower in ketotic cows, abundance of ORAI1 protein was greater and was associated with greater mRNA abundance of ER stress proteins (PERK, IRE1, ATF6, and GRP78) and lipogenic genes (FASN, SREBP1, and $A C A C A$ ). Cellular mechanisms to establish links between BHB and mammary cell responses were evaluated using the immortalized cell line bovine mammary epithelial cells (MAC-T). First, a dose response study was performed with $0,0.6,1.2,1.8,2.4$, or $4.8 \mathrm{~m} M \mathrm{BHB}$ for $24 \mathrm{~h}$. The mRNA abundance of FASN, SREBP1, and $A C A C A$ and lipid droplet formation peaked at $1.2 \mathrm{~m} M$ BHB. A subsequent study involved transfecting MAC-T with small interfering Orai 1 (siORAI1)

\footnotetext{
Received August 7, 2019.

Accepted January 10, 2020.

*These authors contributed equally to this work.

†Corresponding author: xuchuang7175@163.com
}

or the ORAI1 inhibitor $\mathrm{BTP}_{2}$ for $24 \mathrm{~h}$ followed by a challenge with $1.2 \mathrm{mM}$ BHB for $24 \mathrm{~h}$. Transcription and protein abundance of FASN, SREBP1, ACACA, and ER stress proteins returned to basal levels when ORAI1 was silenced or inhibited. Furthermore, the $\mathrm{Ca}^{2+}$ ionophore ionomycin (raises the intracellular level of $\mathrm{Ca}^{2+}$ ) also increased abundance of ORAI1, FASN, SREBP1, ACACA, and ER stress proteins. Data suggest that the mammary gland experiences ER stress during ketosis, partly due to the greater supply of BHB originating from ketogenesis in the liver. Intracellular $\mathrm{Ca}^{2+}$ signaling and ORAI1 seem to mediate in part the BHB-induced ER stress in mammary cells.

Key words: $\mathrm{Ca}^{2+}$ signaling, dairy cow, lactation, stress

\section{INTRODUCTION}

The transient state of negative energy balance (NEB) that cows experience especially after calving renders them highly susceptible to ketosis, a major metabolic disorder associated with decreased milk production and removal from the herd (Loor et al., 2013; Osorio et al., 2013; Sun et al., 2019). To compensate for the deficiency in energy supply in early lactation, body fat reserves are mobilized, resulting in an increase of plasma concentrations of nonesterified fatty acids (NEFA; Schultz, 1968; Baird, 1982). Although some NEFA are used for milk fat synthesis, large portion are metabolized to ketone bodies in the liver, primarily BHB. The close association between adipose lipolysis and both NEFA and BHB renders these 2 biomarkers suitable indicators of subclinical or clinical ketosis (Oetzel, 2004). Although hepatic metabolic and molecular adaptations to NEB are relatively well known (e.g., Loor et al., 2007), besides well-described changes in protein and fat content of milk, less is known about the biologic response of mammary cells to high concentrations of NEFA, BHB, or both (Zhang et al., 2015). 
In nonruminants, Orai calcium release-activated calcium modulator 1 (ORAI1) is a key component of the store-operated $\mathrm{Ca}^{2+}$ entry (SOCE) mechanism regulating cellular $\mathrm{Ca}^{2+}$. At least in rodents, the ORAI1 protein [located at the basolateral membranes in mammary epithelial cells (Cross et al., 2013)] plays a role in the control of intracellular $\mathrm{Ca}^{2+}$ during lactation (McAndrew et al., 2011). Besides its well-known signaling and metabolic properties in mammary cells, $\mathrm{Ca}^{2+}$ also plays a role in the control of endoplasmic reticulum (ER) signaling cascades, for example, the unfolded protein response (UPR) within the ER lumen (Fu et al., 2012; Zhu et al., 2016; Yu et al., 2018). Three protein sensors on the ER membrane initiate the UPR: inositol-requiring kinase 1 (IRE1), pancreatic ER eukaryotic translation initiation factor 2 (eIF2a) kinase (PERK), and activating transcription factor 6 (ATF6). Binding of the ER luminal protein chaperone $\mathrm{BiP} /$ glucose-regulated protein 78 (GRP78) to the UPR sensors prevents their signaling.

Besides the well-established role of ORAI1 in $\mathrm{Ca}^{2+}$ homeostasis, data in nonruminants link ORAI1 and lipogenesis. For instance, silencing of ORAI1 decreased nuclear sterol regulatory element-binding protein 1 (SREBP1) in rat hepatocytes and produced a dramatic decrease in fatty acid (FA) synthesis (Zhang et al., 2018). A link between ER stress proteins and the onset of lactation in bovine mammary gland was previously reported (Invernizzi et al., 2012). However, it is unknown to what extent an association is present between ORAI1, ER stress, and metabolism in bovine mammary cells. By evaluating some of the key regulators of lipogenesis such as SREBP1 (Bionaz and Loor, 2008) and fatty acid synthase (FASN) during cellular stress caused by the onset of ketosis, a better characterization of the functional changes that the mammary gland undergoes could be made.

The general hypothesis of the present work was that elevated concentrations of BHB cause ER stress and changes in lipogenesis in mammary cells. The main objective was to establish the role of ORAI1 and $\mathrm{Ca}^{2+}$ signaling in those processes. A combination of in vivo and in vitro analyses was performed to achieve that aim.

\section{MATERIALS AND METHODS}

The Ethics Committee for the Use and Care of Animals, Heilongjiang Bayi Agricultural University (Daqing, China) approved the animal use protocol.

\section{Sample Collection}

Lactating multiparous Holstein cows $(10.13 \pm 1.90 \mathrm{~d}$ postpartum, parity $2.8 \pm 0.7$, BCS $2.92 \pm 0.15$ ) from a commercial dairy farm (Heilongjiang Province, China) received a routine physical examination by the attending veterinarian before selection for the study. Cows were suspected of being clinically ketotic if feed intake, milk yield, or both were reduced and a nitroprusside test for ketone bodies in milk was positive. Actual milk production and "standard" lactation curves were compared (Wilmink, 1987) as part of selecting potential cows for the study [i.e., cows with actual milk yield with more than $5 \mathrm{~kg} / \mathrm{d}$ below a standard lactation curve within $2 \mathrm{~d}$ postpartum were deemed suitable for further confirmation of ketosis (Silvestre et al., 2006)]. The concentration of plasma BHB was used to confirm ketosis. Subsequently, 6 cows having plasma BHB $>2.0$ $\mathrm{mmol} / \mathrm{L}$ were selected for mammary biopsies. Another 6 cows with plasma $\mathrm{BHB}<0.60 \mathrm{mmol} / \mathrm{L}$ and no obvious signs of ketosis were selected as healthy controls. Characteristics of the ketotic and healthy cows are in Table 1. Concentration of BHB was measured by an automatic biochemical analyzer (Synchron DXC800; Beckman Coulter Inc., Brea, CA). Cows were housed individually in free stalls. Cows were milked 3 times daily at 0400,1200 , and $2000 \mathrm{~h}$ via an automatic milk system (Supplemental Table S1, https://doi.org/10 .3168/jds.2019-17422).

Percutaneous biopsies from the midpoint of one the rear quarters were obtained according to published procedures (Bionaz and Loor, 2008). Biopsies were conducted at $0630 \mathrm{~h}$ (after the morning milking).

Table 1. Basic features of healthy and clinically ketotic cows used in the present study

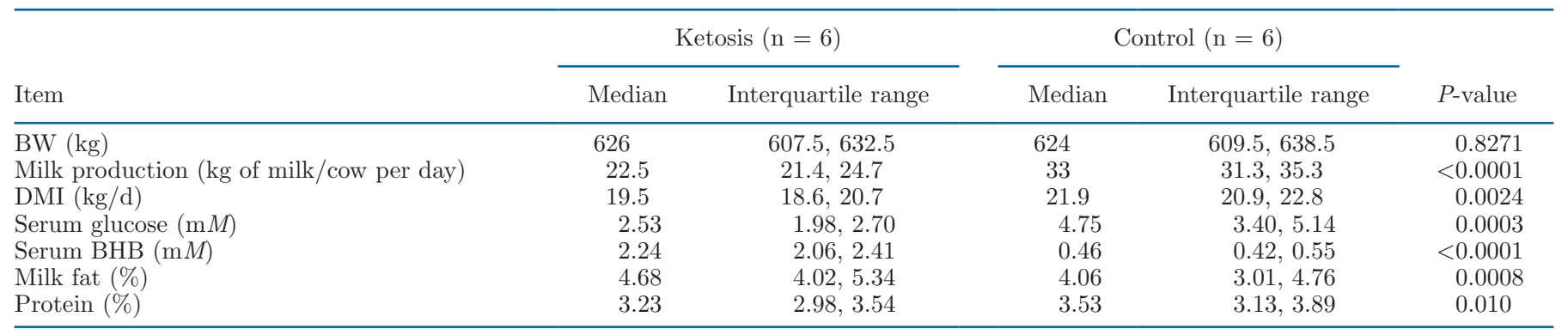


Briefly, cows were administered an i.m. injection of $2 \%$ lidocaine $(0.05 \mathrm{mg} / \mathrm{kg}$ of BW; $2 \%$ Seractal, Bayer, Leverkusen, Germany). The mammary gland tissue was scrubbed with Iodine Tincture (ANNJET Pharma, Shandong, China) and 70\% ethanol. After making the skin incision, blunt dissection of the mammary capsule was used to ensure tissue obtained during the biopsy was mammary parenchyma. Immediately after removal of the biopsy instrument from the capsule, pressure was applied to the entry point to reduce blood accumulation under the skin. The skin incision was closed with 4 or 5 Michel clips (11 mm; Henry Schein, Melville, NY). The collected samples were rinsed with saline solution and immediately frozen in liquid nitrogen. Samples were stored at $-80^{\circ} \mathrm{C}$ until analyses.

\section{Cell Culture}

Immortalized bovine mammary epithelial cells (MAC-T) were a kind gift from Shandong Agricultural University (Taian, China). Bovine mammary epithelial cells were cultured in $75-\mathrm{cm}^{2}$ cell culture flasks using Dulbecco's modified Eagle medium/F12 medium supplemented with $10 \%$ fetal bovine serum, $100 \mathrm{U} / \mathrm{mL}$ penicillin, and $100 \mu \mathrm{g} / \mathrm{mL}$ streptomycin in an incubator at $37^{\circ} \mathrm{C}$ incubator with $5 \% \mathrm{CO}_{2}$. When cell density reached $80 \%$, cells were detached with $0.05 \%$ trypsin, $0.53 \mathrm{mM}$ EDTA, and incubated at $37^{\circ} \mathrm{C}$ for $5 \mathrm{~min}$ before passage into new cell culture flasks. Cells were then resuspended in culture medium and seeded in 6-well plates at a density of $4 \times 10^{5}$ cells $/ \mathrm{cm}^{2}(2 \mathrm{~mL}$ per well). Before treatments, cells were passaged 3 times. Medium was changed once in $48 \mathrm{~h}$. Approximately $24 \mathrm{~h}$ before applying treatments, cells were cultured in lactogenic medium (Kadegowda et al., 2009). The lactogenic medium was Dulbecco's modified Eagle medium/F12 medium supplemented with BSA $(1 \mathrm{~g} / \mathrm{L})$ and prolactin $(2.5 \mathrm{mg} / \mathrm{L})$.

\section{Dose Response with $B H B$ and Transfections}

The sodium salt of BHB was used for in vitro challenge (Sigma-Aldrich). Before culture, BHB powder was dissolved in distilled water and sterilized by filtration. Before treatments, cells were serum-starved for 12 h. Mammary epithelial cells were cultured in serum-free medium with $0,0.6,1.2,1.8,2.4$, and $4.8 \mathrm{mM}$ BHB for $24 \mathrm{~h}$.

For transient transfection, according to our previous research (Zhang et al., 2019), $4 \times 10^{5}$ cells (6-well plate) were seeded $24 \mathrm{~h}$ before the experiment and then transfected with $40 \mathrm{p} M$ bovine Orail small interfering RNA (siRNA; Shanghai GenePharma Co., Ltd., Shanghai, China) or nontargeting siRNA (Shanghai
GenePharma Co., Ltd.) using siRNA-Mate transfection reagent (Shanghai GenePharma Co., Ltd.) according to the manufacturer's protocol (http://www.genepharma $. \mathrm{com} /$ show.php?ctype $=0 \&$ coupid $=568 \&$ cateid $=111)$.

\section{Inhibition of ORAl1}

Before treatment with ORAI1 inhibitor, cells were seeded in 6 -well plates at a density of $4 \times 10^{5}$ cells/ $\mathrm{cm}^{2}$ (2 $\mathrm{mL}$ per well) with DMEM/F12 medium supplemented containing $10 \%$ fetal bovine serum, $100 \mathrm{U} /$ $\mathrm{mL}$ penicillin, and $100 \mu \mathrm{g} / \mathrm{mL}$ streptomycin at $37^{\circ} \mathrm{C}$ with $5 \% \mathrm{CO}_{2}$ for $24 \mathrm{~h}$. The $\mathrm{Ca}^{2+}$ ionophore ionomycin (Sigma, Beijing, China) and ORAI1 inhibitor $\mathrm{N}$-(4[3,5-bis(trifluoromethyl)-1H-pyrazol-1-yl]-phenyl)4methyl-1,2,3-thiadiazole-5-carboxamide $\left(\mathbf{B T P}_{2}\right.$; Sigma, Beijing, China) were used in these studies, respectively. After the 24-h culture period, cells were split into 4 culture groups: control, $\mathrm{BHB}, \mathrm{BTP}_{2}$, and $\mathrm{BTP}_{2}+\mathrm{BHB}$. The concentration of $\mathrm{BTP}_{2}$ was $20 \mu M$, which was applied for $2 \mathrm{~h}$ before addition of $1.2 \mathrm{mM}$ BHB. For $\mathrm{Ca}^{2+}$ ionophore addition, $4 \times 10^{5}$ cells (6-well plate) were seeded $24 \mathrm{~h}$ before the experiment. Then, ionomycin was added to MAC-T cells and incubated for $6 \mathrm{~h}$.

\section{RNA Extraction and Quantitative Real-Time PCR}

Total RNA was isolated from MAC-T cells using TRIzol (Invitrogen Corporation, Carlsbad, CA) according to the manufacturer's protocol (https://assets .thermofisher.com/TFS-Assets/LSG/manuals/trizol _reagent.pdf); mRNA was reverse transcribed with Reverse Transcriptase M-MLV (RNase H-, Takara Bio Inc., Otsu, Japan) using an oligodT primer. Quantitative real-time (qRT)-PCR was performed on a BioRad iCycler iQTM Real-Time PCR Detection System (BioRad Laboratories Inc., Hercules, CA).

The qRT-PCR reaction mixture contained $2 \mu \mathrm{L}$ of cDNA, $1 \mu M$ of each primer, $10 \mu \mathrm{L}$ of FastStart Universal SYBR Green Master (F. Hoffmann-La Roche AG, Basel, Switzerland), and sterile water for a final volume of $20 \mu \mathrm{L}$; qRT-PCR conditions were $95^{\circ} \mathrm{C}$ for $3 \mathrm{~min}$, followed by 40 cycles at $95^{\circ} \mathrm{C}$ for $10 \mathrm{~s}$ and $58^{\circ} \mathrm{C}$ for $30 \mathrm{~s}$. Calculated mRNA abundance levels were normalized to B-actin $(A C T B)$ using the $2^{-\triangle \Delta \mathrm{CT}}$ method. The primers used for ORAI1, SREBP1, FASN, PERK, IRE1, ATF6, GRP 78 , and $A C T B$ are reported in Table 2.

\section{Protein Extraction and Western Blotting}

Total protein from mammary tissue and cultured mammary epithelial cells was lysed using RIPA buffer (Beyotime Biotechnology, Jiangsu, China) containing protease inhibitors, incubated on ice for $30 \mathrm{~min}$, and 
centrifuged at $14,000 \times g$ for $5 \mathrm{~min}$ at $4^{\circ} \mathrm{C}$. Protein content was determined using the BCA protein assay kit (Beyotime Biotechnology). Subsequently, equal amounts of protein $(30 \mu \mathrm{g} /$ lane $)$ were separated on $10 \%$ SDS-PAGE and electro-transferred onto polyvinylidene difluoride membrane (Millipore Corp., Billerica, MA). Then, the membrane was blocked for $1 \mathrm{~h}$ at room temperature in $0.1 \%$ Triton-X/PBS containing $5 \%$ skim milk powder (blocking buffer). The blocked membranes were incubated overnight at $4^{\circ} \mathrm{C}$ with specific antibodies for GRP78 (1:250, sc-376768; Santa Cruz Biotechnology, Santa Cruz, CA), PERK (1:1,000, C33E18; Cell Signaling, Danvers, MA), phospho-PERK antibody (1:500, 3179; Cell Signaling), IRE1 (1:1,000, ab37073; Abcam, Burlingame, CA), phospho-IRE1 $\alpha$ antibody (1:500; ab104157, Abcam), ATF6 (1:1,000, ab03119; Abcam), SREBP1 (1:1,000, NB100-2215; Novus Biologicals, Littleton, CO), ORAI1 (1:1,000, 66223-1-Ig; ProteinTech, Rosemont, IL), FASN (1:1,000, 3180; Cell Signaling), ACACA (1:1,000, 3662; Cell Signaling, Danvers, MA), and $\beta$-actin (internal control; 1:1,000, sc-47778; Santa Cruz Biotechnology). Immunoreactive bands were detected using an enhanced chemiluminescence solution (Beyotime Biotechnology). Subsequently, the membranes were incubated with HRP-conjugated secondary antibodies (3:5,000; Beyotime Biotechnology) for $30 \mathrm{~min}$ at room temperature. The protein abundance signals were visualized by ECL (Beyotime Biotechnology) using a protein simple imager (ProteinSimple, San Jose, CA). Band intensity was quantified using the Image Lab software (Bio-Rad Laboratories Inc.).

\section{Lipid Droplet Fluorescence Assay}

According to the BHB dose response study, 1.2 and $1.8 \mathrm{~m} M$ BHB were deemed the best to construct a "ketosis model" in vitro. After treatment with $0,1.2$, or $1.8 \mathrm{~m} M$ BHB for $24 \mathrm{~h}$, MAC-T cells were washed twice with PBS for 5 min, fixed with $4 \%$ paraformaldehyde for $30 \mathrm{~min}$, and then gently washed 3 times with PBS. Lipid droplet fluorescence was done after staining with BODIPY 493/503 (Invitrogen Corporation) according to the manufacturer's instructions. Cells were then washed with PBS for 3 times in the dark. The nuclei were then stained with Hoechst (Beyotime Biotechnology) for $8 \mathrm{~min}$ at room temperature. Cells were then washed 3 times with PBS and fluorescence determined using an inverted microscope (IX73, Olympus, Tokyo, Japan).

\section{Immunofluorescence of ORAl1 Protein}

Immunostaining after transfection with vectors was performed in MAC-T cells plated onto 6-well plates. Washing was done with PBS before fixing with $4 \%$ paraformaldehyde for $30 \mathrm{~min}$ at room temperature. For blocking unspecific binding, the samples were incubated with 3\% Albumin Fraktion V (Carl Roth, Karlsruhe, Germany), 5\% normal goat serum (Sigma, Schnelldorf, Germany), and $0.5 \%$ Triton in PBS (PAA, Cölbe, Germany) for 30 min at room temperature. Cells were then exposed to ORAI1 rabbit polyclonal antibody (1:500, ProteinTech) at $4^{\circ} \mathrm{C}$ in a humidified chamber overnight. Cells were then rinsed 4 times with PBS and incubated

Table 2. Sequences of primers used for real-time PCR amplification

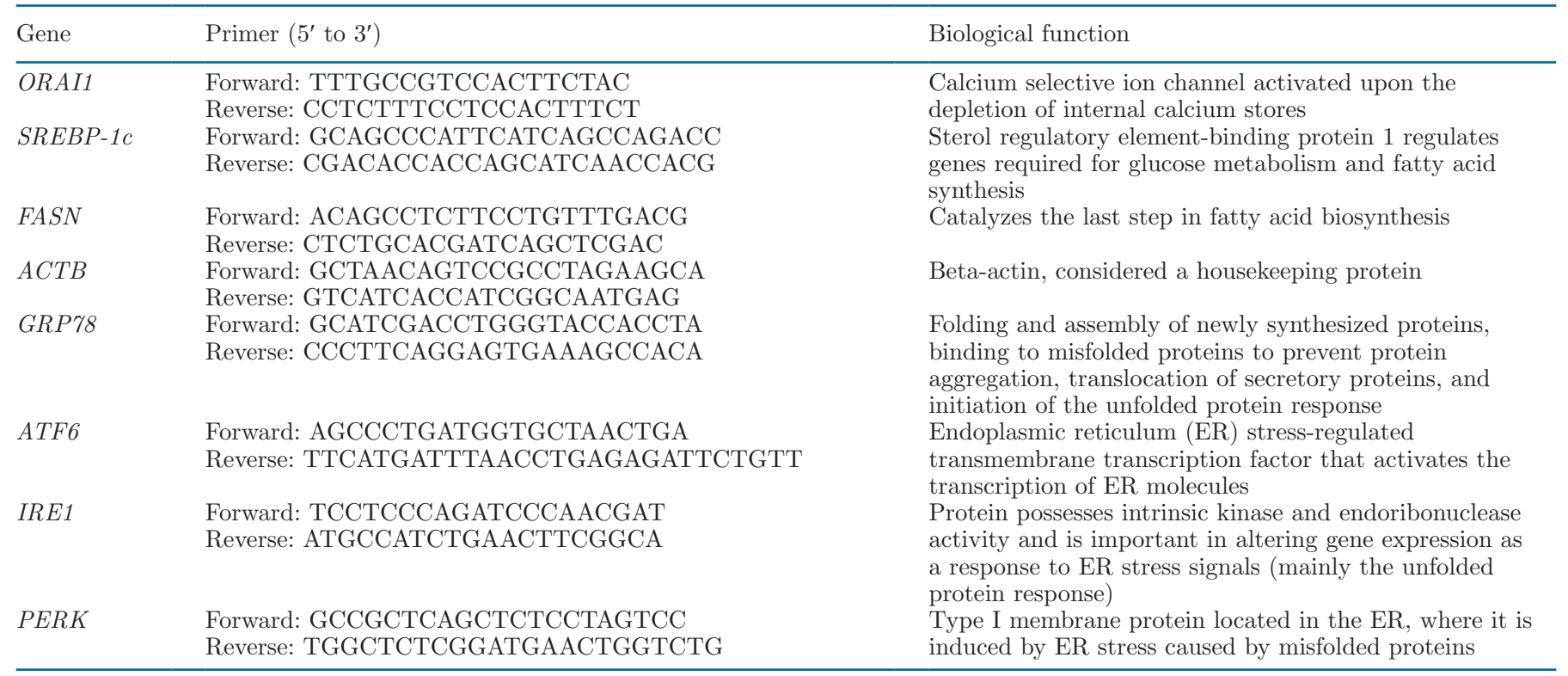


with DyLight 488-conjugated goat anti-rabbit antibody (1:3,000, BIOZOL, Eching, Germany) for $1 \mathrm{~h}$ at room temperature. After 4 washing steps the nuclei were stained with Hoechst (Beyotime Biotechnology) for 8 min at room temperature. After washing 3 times and covering with a glass coverslip, the image was collected with a laser confocal microscope (LSM 5 PASCAL, Zeiss, Oberkochen, Germany). The fluorescence intensity of ORAI1 was quantified using Image J software (National Institutes of Health, Bethesda, MD).

\section{Statistical Analysis}

All treatments were run in triplicate and results are reported as means \pm standard error of the means. The data were analyzed using SPSS 22.0 (IBM Corp., Armonk, NY). Statistical significance was evaluated by 1-way ANOVA with a Duncan test for post-hoc analysis. Differences with $P<0.05$ were considered statistically significant.

\section{RESULTS AND DISCUSSION}

\section{ER Stress, Lipogenesis, and ORAl1 Abundance}

Excessive NEB-induced lipid mobilization leads to hyperketonemia, resulting in high blood concentrations of BHB and greater milk fat percentage (Table 1; Duffield et al., 2009). The high concentrations of BHB are thought to influence milk fat synthesis. Furthermore, in rodents, the ORAI1 protein plays a role in the control of intracellular $\mathrm{Ca}^{2+}$, which controls ER signaling cascades during lactation (Davis et al., 2015). However, it is unknown to what extent an association is present between ORAI1, ER stress, and lipogenesis in bovine mammary cells of dairy cows with ketosis.

As indicated in Figure 1A and B, mammary cells from cows with ketosis had greater $(P<0.05)$ abundance of FASN, SREBP1, GRP78, PERK, IRE1, ATF6, and ORAI1 proteins and had greater $(P<0.01)$ abundance of phospho-PERK and phospho-IRE1 (the representative images are shown in Supplemental Figure S1, https://doi.org/10.3168/jds.2019-17422). Incubation with increasing concentrations of BHB resulted in a dose-dependent change in the mRNA abundance of SREBP1 and FASN, with significantly greater levels at the $1.2 \mathrm{~m} M$ dose of BHB compared with the control group (Figure 2A; $P<0.01$ ). Furthermore, lipid droplet staining results revealed an increase of lipid accumulation in mammary epithelial cells in the $1.2 \mathrm{mM}$ BHB-treated group (Figure 2B). Abundance of ORAI1 mRNA was greater at the $1.2 \mathrm{~m} M$ BHB dose (Figure $2 \mathrm{C}$ ). Immunofluorescence confirmed upregulation of ORAI1 in mammary epithelial cells incubated with 1.2
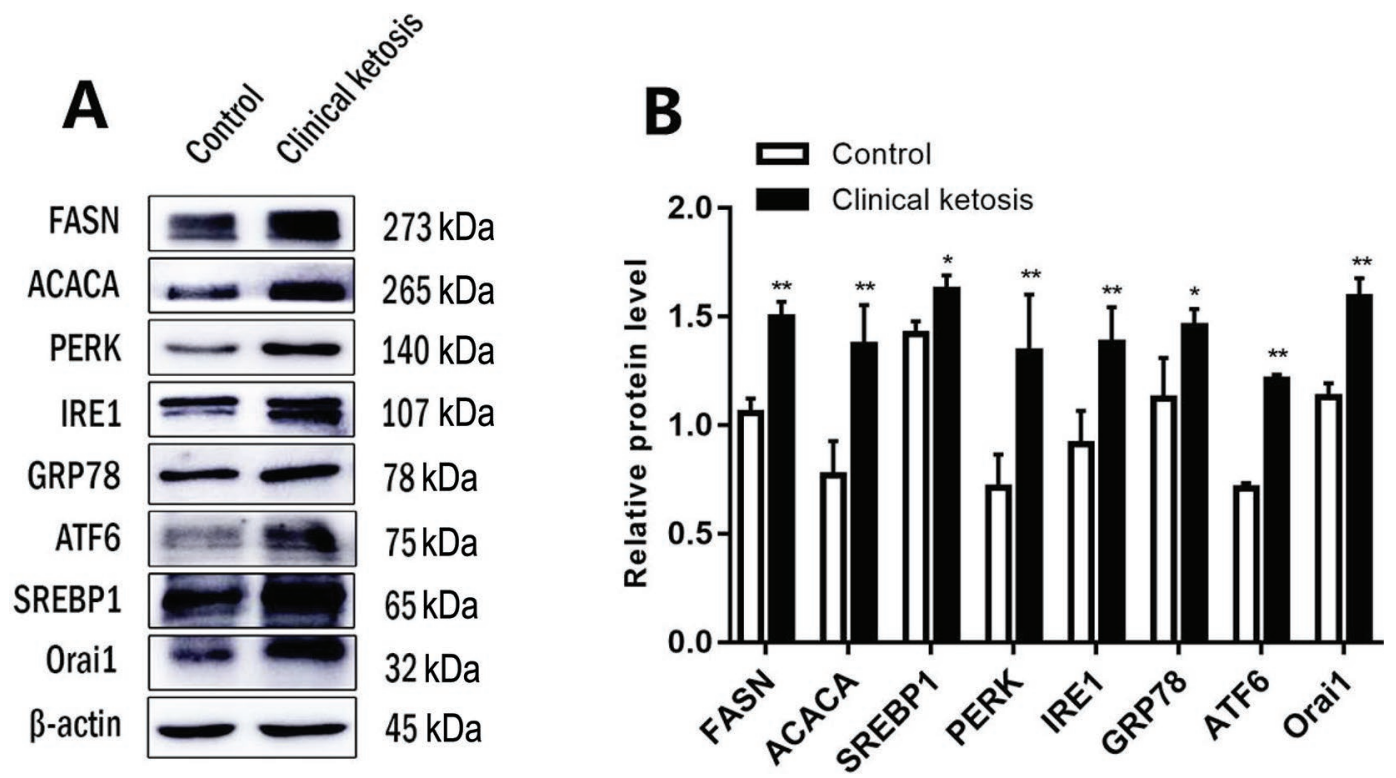

Figure 1. Abundance of fatty acid synthase (FASN), acetyl-CoA carboxylase alpha (ACACA), protein kinase R-like endoplasmic reticulum kinase (PERK), inositol-requiring kinase 1 (IRE1), glucose-regulated protein 78 (GRP78), activating transcription factor 6 (ATF6), sterol regulatory element-binding protein 1 (SREBP1), and Orai calcium release-activated calcium modulator 1 (ORAI1) protein was increased in mammary gland tissue of cows with clinical ketosis. (A) Western blot analysis of FASN, ACACA, PERK, IRE1, GRP78, ATF6, SREBP1, and ORAI1. (B) Relative protein abundance of FASN, ACACA, PERK, IRE1, GRP78, ATF6, SREBP1, and ORAI1. The data of the control group were used to normalize the data of the cows with clinical ketosis group. The data were analyzed with paired $t$-tests and expressed as the mean $\pm \operatorname{SEM}\left(\mathrm{n}=6\right.$ per group). ${ }^{*} P<0.05,{ }^{* *} P<0.01$. 
$\mathrm{m} M$ BHB (Figure 2D). Overall, these data suggested a positive correlation between high blood BHB concentrations and lipogenic response in mammary cells due in part to ER stress and ORAI1 levels.

\section{ORAl1-Sensitive ER Stress Regulates Lipogenesis}

Substantial evidence indicates that SREBP1 plays a key role in the regulation of bovine milk fat synthesis in dairy cows (Osorio et al., 2016), in part through the control of lipogenic enzyme abundance including FASN (Torrens et al., 2014). In addition, overexpression of SREBP increased the mRNA abundance of FASN in bovine mammary epithelial cells (Han et al., 2018). Previous research in nonruminants indicated that ER stress is involved in the course of lipogenesis (Liu et al., 2010). For instance, in mice, ER stress drives hepatic lipogenesis via SREBP1 (Kim et al., 2018). Furthermore, ER stress plays a role in the development of hepatic lipid accumulation in ketotic cows (Khan et al., 2015, Ringseis et al., 2015), which is similar to our findings in that the abundance of GRP78, PERK, IRE1, ATF6, phospho-PERK, phospho-IRE1 protein and lipogenic proteins (SREBP1, FASN) were upregulated both dur- ing ketosis (Figure 1 and Supplemental Figure S2, https: //doi.org/10.3168/jds.2019-17422) and in response to greater in vitro supply of BHB to mammary epithelial cells (Figure 3 and Supplemental Figure S3, https:// doi.org/10.3168/jds.2019-17422). Thus, clinical ketosis potentially through an increase in the influx of BHB and NEFA enhances ER stress and favors the lipogenic response that leads to greater milk fat concentration. In addition, both the greater ORAI1 abundance in mammary gland of cows with clinical ketosis (Figure 1) and the increase in ORAI1 abundance in vitro in response to exogenous BHB (Figure 2C, Figure 3, and Figure 4) suggested a functional link in the mammary gland (McAndrew et al., 2011).

The ORAI protein belongs to the store-operated calcium channel family, which controls channel-mediated $\mathrm{Ca}^{2+}$ influx and signaling (Feske, 2010). Store-operated calcium entry is one of the major extracellular $\mathrm{Ca}^{2+}$ influx pathways (Soboloff et al., 2012). The ER acts as a reservoir for $\mathrm{Ca}^{2+}$ to help maintain intracellular homeostasis. Upon $\mathrm{Ca}^{2+}$ depletion in the ER, ORAI1 channels are activated and promote SOCE (Brandman et al., 2007). Besides the well-established role in $\mathrm{Ca}^{2+}$ homeostasis, work in nonruminants has indicated that
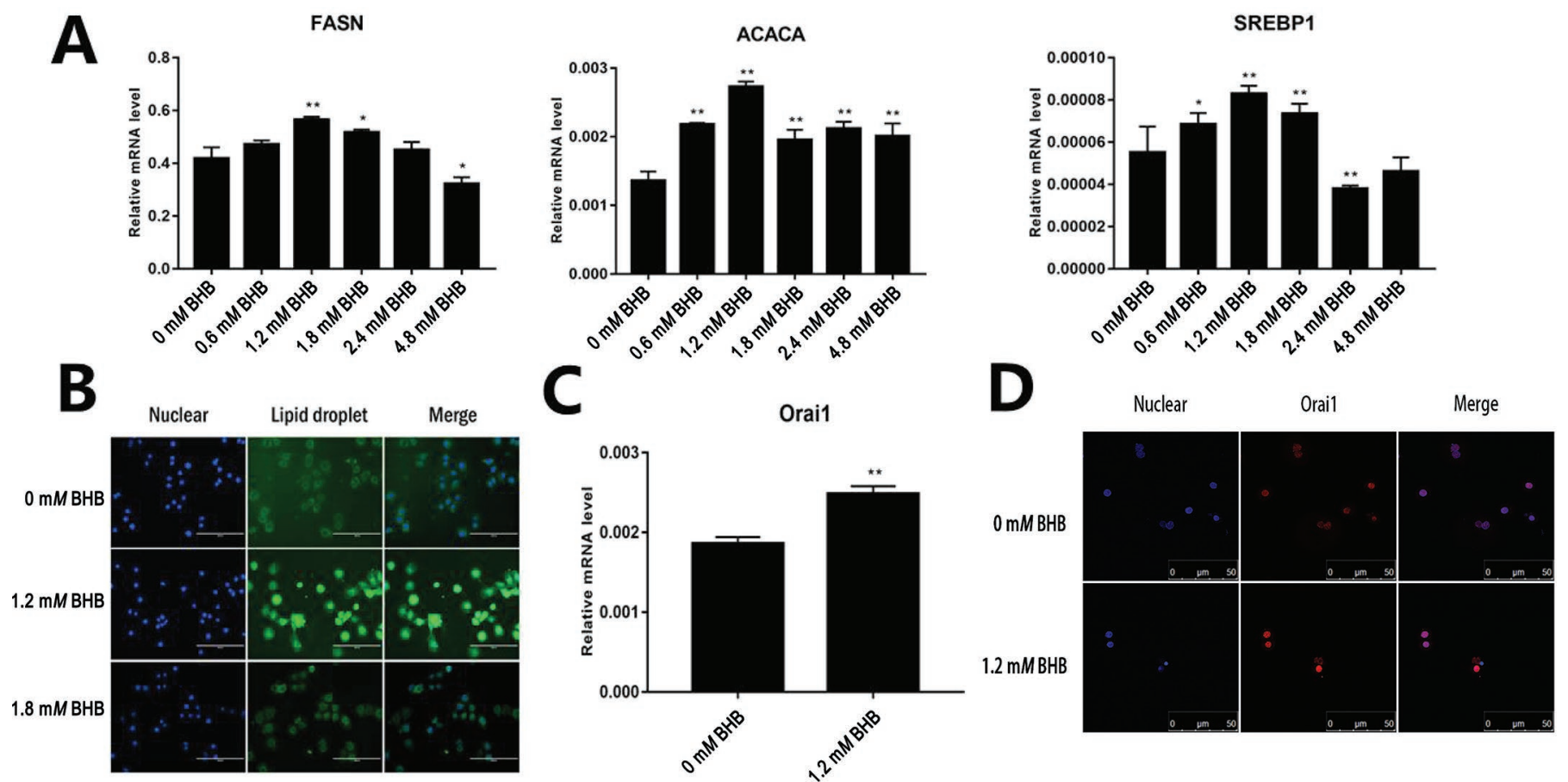

Figure 2. Effect of BHB on fatty acid synthesis, endoplasmic reticulum stress, and Orai calcium release-activated calcium modulator 1 (ORAI1) abundance in bovine mammary epithelial cells. Cells were treated with $0,0.6,1.2,1.8,2.4$, or $4.8 \mathrm{mM}$ BHB for $24 \mathrm{~h}$. (A) Relative mRNA abundance of fatty acid synthase (FASN), acetyl-CoA carboxylase alpha (ACACA), and sterol regulatory element-binding protein 1 (SREBP1; $\mathrm{n}=15$ per group). (B) Lipid droplet staining, scale bar $=200 \mu \mathrm{m}$. The data of the $0 \mathrm{~m} M$ BHB group were used to normalize the data of each treatment group. (C) Relative mRNA abundance of ORAI1 by $1.2 \mathrm{~m} M$ BHB for $24 \mathrm{~h}(\mathrm{n}=15$ per group). (D) Immunofluorescence of ORAI1 protein by $1.2 \mathrm{mM}$ BHB for $24 \mathrm{~h}$; scale bar $=50 \mu \mathrm{m}$. Comparisons among groups were calculated using a 1-way ANOVA with subsequent Duncan correction. The data presented are the mean $\pm \mathrm{SEM} ;{ }^{*} P<0.05,{ }^{* *} P<0.01$. 
A
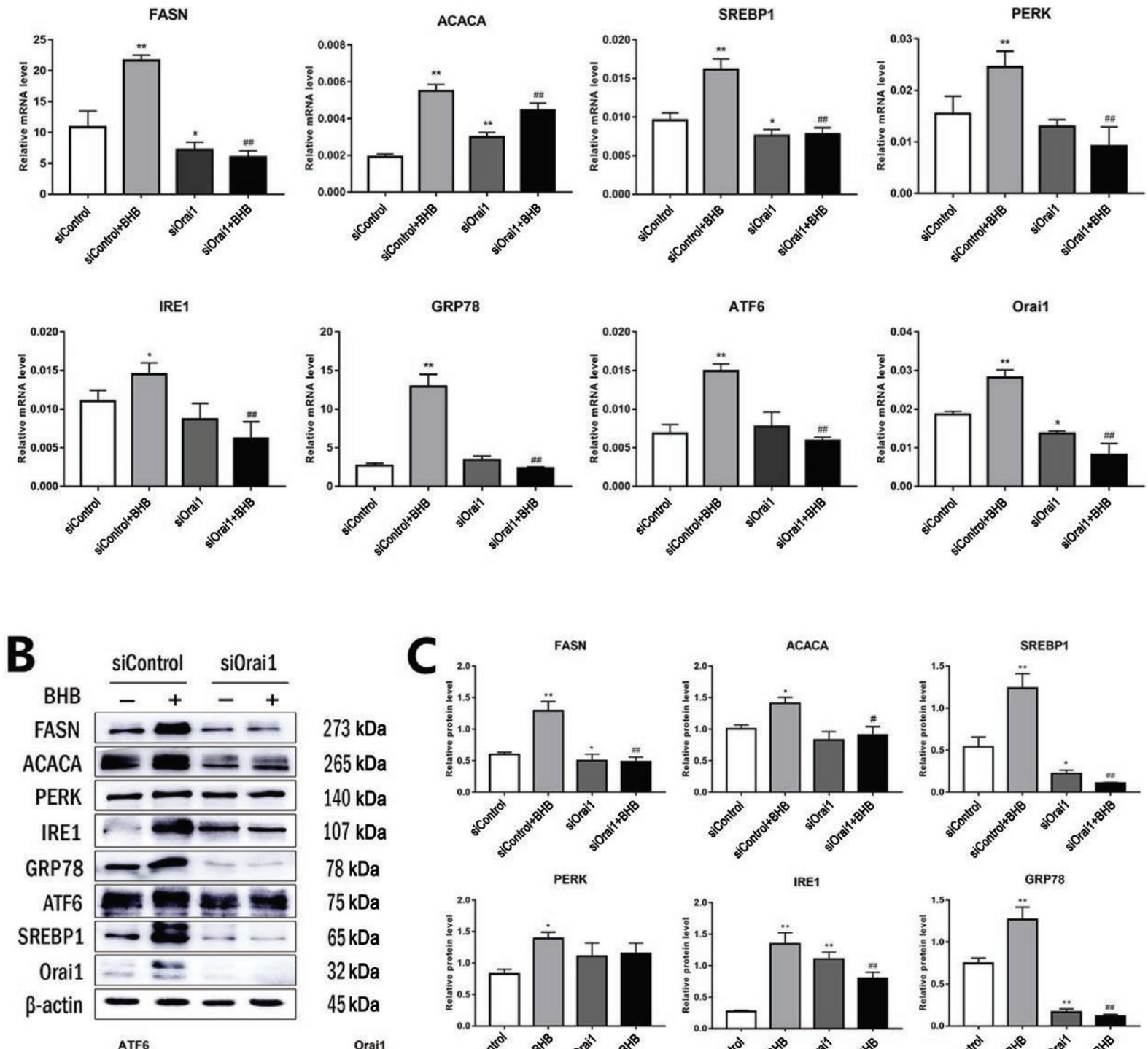

$78 \mathrm{kDa}$

$75 \mathrm{kDa}$

$65 \mathrm{kDa}$

$32 \mathrm{kDa}$

$45 \mathrm{kDa}$
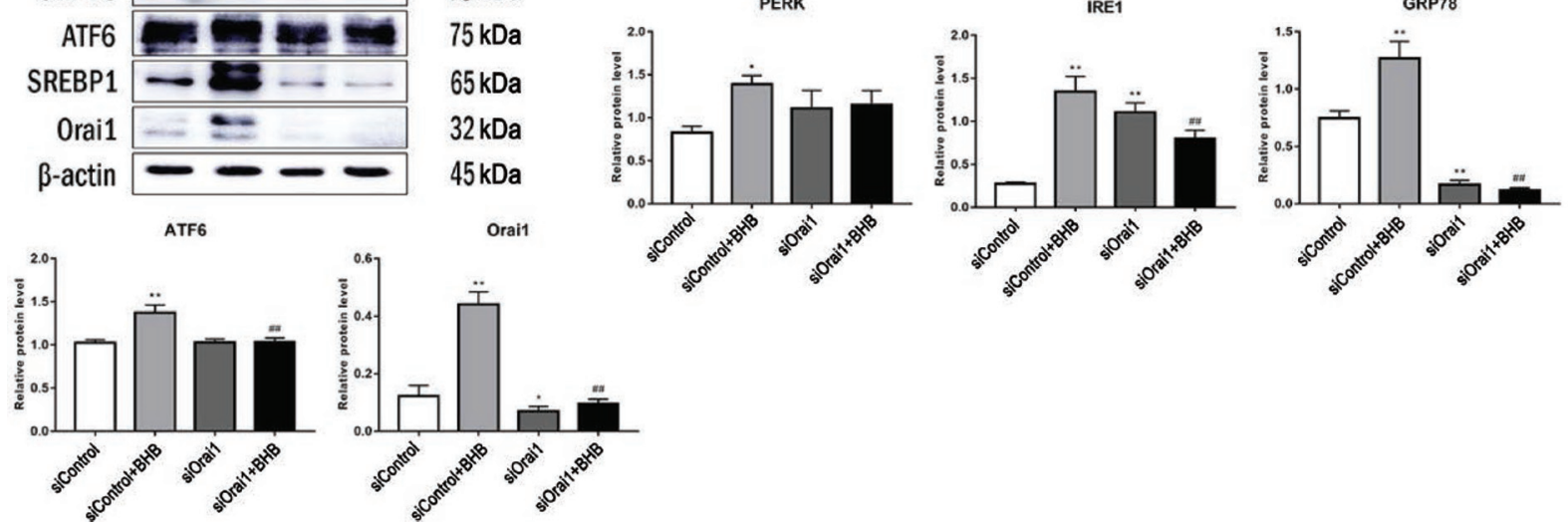

Figure 3. Effect of Orai calcium release-activated calcium modulator 1 (ORAI1) silencing on endoplasmic reticulum stress and fatty acid synthesis in bovine mammary epithelial cells. The immortalized bovine mammary epithelial (MAC-T) cells were divided into 4 groups as follows: control siRNA group [cells were infected with small interfering RNA (siRNA)-Mate (Shanghai GenePharma Co., Ltd., Shanghai, China) for $24 \mathrm{~h}$ ], control siRNA $+1.2 \mathrm{~m} M$ BHB group (cells were infected with siRNA-Mate for $24 \mathrm{~h}$ and then treated with $1.2 \mathrm{~m} M$ BHB for another 24 h), Orai transient transfection (siORAI1) group (cells were transient transfected with siORAI1 for $24 \mathrm{~h}$ ), and siORAI1 + $1.2 \mathrm{~m} M$ BHB group (transfection with siORAI1 for $24 \mathrm{~h}$ and then treated with $1.2 \mathrm{mM}$ BHB for another $24 \mathrm{~h}$ ). (A) Relative mRNA abundance of fatty acid synthase (FASN), acetyl-CoA carboxylase alpha (ACACA), protein kinase R-like endoplasmic reticulum kinase (PERK), inositol-requiring kinase 1 (IRE1), glucose-regulated protein 78 (GRP78), activating transcription factor 6 (ATF6), sterol regulatory element-binding protein 1 (SREBP1), and ORAI1 ( $\mathrm{n}=15$ per group). (B) Western blot analysis of FASN, ACACA, PERK, IRE1, GRP78, ATF6, SREBP1, and ORAI1. (C) Relative protein abundance of FASN, ACACA, PERK, IRE1, GRP78, ATF6, SREBP1, and ORAI1 ( $\mathrm{n}=15$ per group). The data of the control siRNA group were used to normalize the data of each treatment group. Comparisons among groups were calculated using a 1-way ANOVA with subsequent Duncan correction. The data presented are the mean $\pm \mathrm{SEM} ;{ }^{*} P<0.05,{ }^{* *} P<0.01$ indicate differences from control. \#P<0.05, \#\#P $<0.01$ indicate differences from BHB alone. 
A
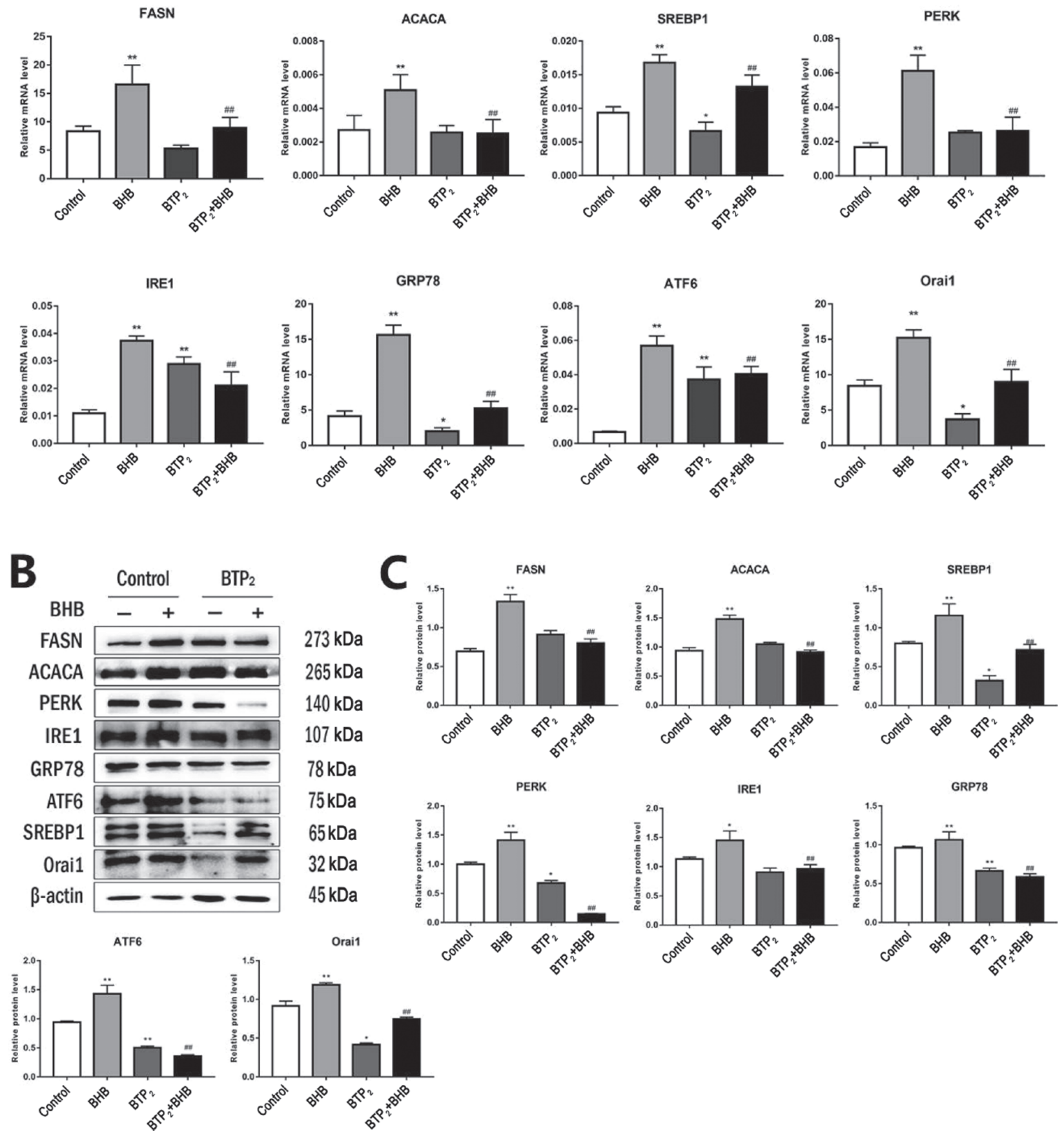

Figure 4. Effect of Orai calcium release-activated calcium modulator 1 (ORAI1) inhibitor on endoplasmic reticulum stress and fatty acid synthesis in bovine mammary epithelial cells. The cells were divided into 4 groups as follows: control group (cells were cultured in Dulbecco's modified Eagle medium/F12 for $24 \mathrm{~h}$ ), $1.2 \mathrm{mM}$ BHB group (cells were treated with $1.2 \mathrm{~m} M$ BHB for $24 \mathrm{~h}$ ), BTP 2 group (cells were treated with $20 \mu M \mathrm{BTP}_{2}$ for $2 \mathrm{~h} ; \mathrm{BTP}_{2}=\mathrm{N}$-(4-[3,5-bis(trifluoromethyl)-1H-pyrazol-1-yl]-phenyl)4-methyl-1,2,3-thiadiazole-5-carboxamide), and BTP $2+1.2$ $\mathrm{m} M$ BHB group $\left(\mathrm{BTP}_{2}\right.$ was used for $2 \mathrm{~h}$ before BHB and then treated with $1.2 \mathrm{mM}$ BHB for another $\left.24 \mathrm{~h}\right)$. (A) Relative mRNA abundance of fatty acid synthase (FASN), acetyl-CoA carboxylase alpha (ACACA), protein kinase R-like endoplasmic reticulum kinase (PERK), inositolrequiring kinase 1 (IRE1), glucose-regulated protein 78 (GRP78), activating transcription factor 6 (ATF6), sterol regulatory element-binding protein 1 (SREBP1), and ORAI1 ( $\mathrm{n}=15$ per group). (B) Western blot analysis of FASN, ACACA, PERK, IRE1, GRP78, ATF6, SREBP1, and ORAI1. (C) Relative protein abundance of FASN, ACACA, PERK, IRE1, GRP78, ATF6, SREBP1, and ORAI1 (n = 15 per group). The data of the control group were used to normalize the data of each treatment group. Comparisons among groups were calculated using a 1-way ANOVA with subsequent Duncan correction. The data presented are the mean \pm SEM. ${ }^{*} P<0.05,{ }^{* *} P<0.01$ indicate differences from control. $\# P<0.05, \# \# P<0.01$ indicate differences from BHB alone. 
A
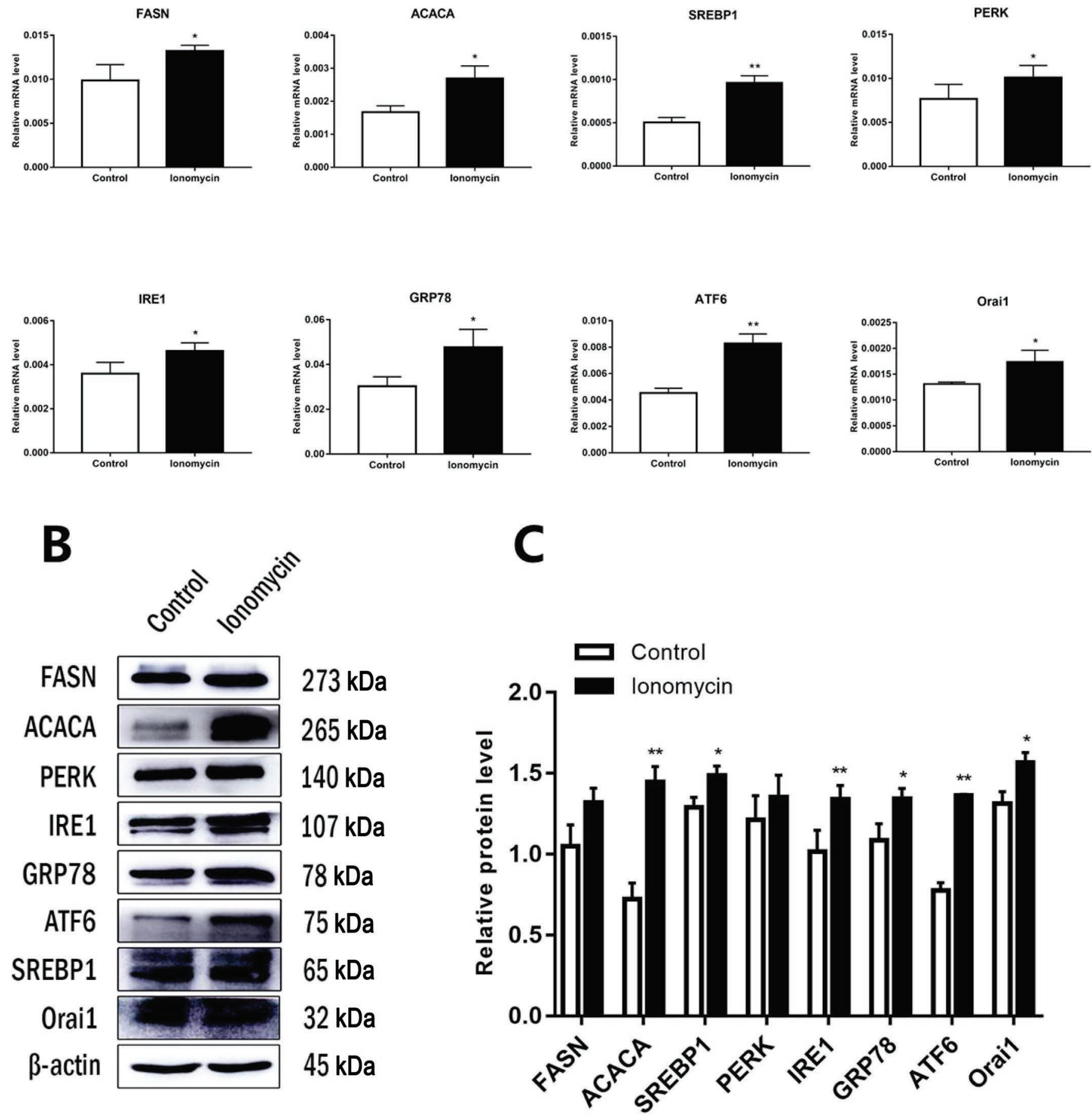

Figure 5. Effect of intracellular calcium concentration on fatty acid synthesis, endoplasmic reticulum stress, and Orai calcium release-activated calcium modulator 1 (ORAI1) abundance in bovine mammary epithelial cells. Cells were treated with 50 mM ionomycin for 6 h. (A) Relative mRNA abundance of fatty acid synthase (FASN), acetyl-CoA carboxylase alpha (ACACA), protein kinase R-like endoplasmic reticulum kinase (PERK), inositol-requiring kinase 1 (IRE1), glucose-regulated protein 78 (GRP78), activating transcription factor 6 (ATF6), sterol regulatory element-binding protein 1 (SREBP1), and ORAI1 ( $=15$ per group). (B) Western blot analysis of FASN, ACACA, PERK, IRE1, GRP78, ATF6, SREBP1, and ORAI1. (C) Relative protein abundance of FASN, ACACA, PERK, IRE1, GRP78, ATF6, SREBP1, and ORAI1 (n = 15 per group). The data were analyzed with paired $t$-tests and expressed as the mean \pm SEM. ${ }^{*} P<0.05,{ }^{* *} P<0.01$. 
ORAI1 could regulate the expression of SREBP1 and FASN in the liver (Zhang et al., 2018).

In this study, ORAI1 silencing in mammary cells via siRNA or inhibition via $\mathrm{BTP}_{2}$ decreased $(P<0.05)$ mRNA and protein abundance of ORAI1 (Figure 3A-C, Figure 4A-C; Supplemental Figures S3 and S4, https:/ /doi.org/10.3168/jds.2019-17422). Such response markedly alleviated the upregulation in mRNA and protein abundance of FASN, SREBP1, PERK, IRE1, phosphoPERK, phospho-IRE1, ATF6, and GRP78 induced by $1.2 \mathrm{mM}$ BHB (Figure $3 \mathrm{~A}-\mathrm{C}$ and Figure $4 \mathrm{~A}-\mathrm{C}$, and Supplemental Figures S3B-C and S4B-C; $P<0.01$ ). In addition, culture with ionomycin $\left(\mathrm{a} \mathrm{Ca}^{2+}\right.$ ionophore that can increase intracellular level of $\mathrm{Ca}^{2+}$ ) led to upregulation of mRNA and protein abundance of ORAI1 (Figure 5A-C; $P<0.05$; Supplemental Figure S4, $P<$ $0.01)$. Furthermore, it markedly increased mRNA and protein abundance of FASN, SREBP1, PERK, IRE1, ATF6, and GRP78 (Figure 5A-C; $P<0.05$ ). Thus, these data suggest a role for ORAI1 in the SREBP1 activation of FASN and lipid droplet formation.

Because silencing of ORAI1 prevented the increase in abundance of de novo FA synthesis genes (FASN and SREBP1) and GRP78 induced by BHB, availability of BHB within mammary cells and the subsequent induction of ER stress might be a signal regulating ORAI1. In $\beta$-TC3 cells, free FA-induced ER stress was mediated SOCE through ORAI1 (Cui et al., 2013). That response agrees with our findings in which addition of ionomycin increased abundance of the ER stress marker GRP78; ER stress protein sensors PERK, IRE1, and ATF6; and abundance of lipogenic proteins. Although we could not discern the exact mechanisms, the data suggest that at least during ketosis ORAI1 may contribute to ER stress and milk fat synthesis.

\section{CONCLUSIONS}

The SOCE moiety ORAI1 regulated SREBP1 to activate FASN and lipid droplet formation through ER stress in dairy cows with ketosis. Thus, ORAI1 mediates in part the development of BHB-induced ER stress and elevation of milk fat content during clinical ketosis.

\section{ACKNOWLEDGMENTS}

This work was supported by the National Natural Science Foundation of China (Beijing, China; grant nos. 31702308 and 31672622), Changjiang Scholar Program of Chinese Ministry of Education (Q2017229), and major projects of applied technology research and development plan in Heilongjiang of China (project no. GA16B202). The authors declare no conflicts of interest.

\section{REFERENCES}

Baird, G. D. 1982. Primary ketosis in the high-producing dairy cow: Clinical and subclinical disorders, treatment, prevention, and outlook. J. Dairy Sci. 65:1-10. https://doi.org/10.3168/jds.S0022 -0302(82)82146-2.

Bionaz, M., and J. J. Loor. 2008. Gene networks driving bovine milk fat synthesis during the lactation cycle. BMC Genomics 9:366. https://doi.org/10.1186/1471-2164-9-366.

Brandman, O., J. Liou, W. S. Park, and T. Meyer. 2007. STIM2 is a feedback regulator that stabilizes basal cytosolic and endoplasmic reticulum $\mathrm{Ca}^{2+}$ levels. Cell 131:1327-1339. https://doi.org/10 $.1016 /$ j.cell.2007.11.039.

Cross, B. M., A. Hack, T. A. Reinhardt, and R. Rao. 2013. SPCA2 regulates Orail trafficking and store independent $\mathrm{Ca}^{2+}$ entry in a model of lactation. PLoS One 8:e67348. https://doi.org/10.1371/ journal.pone.0067348.

Cui, W., J. Ma, X. Wang, W. Yang, J. Zhang, and Q. Ji. 2013. Free fatty acid induces endoplasmic reticulum stress and apoptosis of beta-cells by $\mathrm{Ca}^{2+} /$ calpain- 2 pathways. PLoS One 8:e59921. https: //doi.org/10.1371/journal.pone.0059921.

Davis, F. M., A. Janoshazi, K. S. Janardhan, N. Steinckwich, D. M. D'Agostin, J. G. Petranka, P. N. Desai, S. J. Roberts-Thomson, G. S. Bird, D. K. Tucker, S. E. Fenton, S. Feske, G. R. Monteith, and J. W. Putney Jr.. 2015. Essential role of Orai1 store-operated calcium channels in lactation. Proc. Natl. Acad. Sci. USA 112:58275832. https://doi.org/10.1073/pnas.1502264112.

Duffield, T. F., K. D. Lissemore, B. W. McBride, and K. E. Leslie. 2009. Impact of hyperketonemia in early lactation dairy cows on health and production. J. Dairy Sci. 92:571-580. https://doi.org/ $10.3168 /$ jds.2008-1507.

Feske, S. 2010. CRAC channelopathies. Pflugers Arch. 460:417-435. https://doi.org/10.1007/s00424-009-0777-5.

Fu, S., S. M. Watkins, and G. S. Hotamisligil. 2012. The role of endoplasmic reticulum in hepatic lipid homeostasis and stress signaling. Cell Metab. 15:623-634. https://doi.org/10.1016/j.cmet.2012 .03 .007 .

Han, L. Q., T. Y. Gao, G. Y. Yang, and J. J. Loor. 2018. Overexpression of SREBF chaperone (SCAP) enhances nuclear SREBP1 translocation to upregulate fatty acid synthase (FASN) gene expression in bovine mammary epithelial cells. J. Dairy Sci. 101:6523-6531. https://doi.org/10.3168/jds.2018-14382.

Invernizzi, G., A. Naeem, and J. J. Loor. 2012. Short communication: Endoplasmic reticulum stress gene network expression in bovine mammary tissue during the lactation cycle. J. Dairy Sci. 95:25622566. https://doi.org/10.3168/jds.2011-4806.

Kadegowda, A. K., M. Bionaz, L. S. Piperova, R. A. Erdman, and J. J. Loor. 2009. Peroxisome proliferator-activated receptor-gamma activation and long-chain fatty acids alter lipogenic gene networks in bovine mammary epithelial cells to various extents. J. Dairy Sci. 92:4276-4289. https://doi.org/10.3168/jds.2008-1932.

Khan, M. J., C. B. Jacometo, M. V. Riboni, E. Trevisi, D. E. Graugnard, M. N. Correa, and J. J. Loor. 2015. Stress and inflammatory gene networks in bovine liver are altered by plane of dietary energy during late pregnancy. Funct. Integr. Genomics 15:563-576. https: //doi.org/10.1007/s10142-015-0443-2.

Kim, J. Y., R. Garcia-Carbonell, S. Yamachika, P. Zhao, D. Dhar, R. Loomba, R. J. Kaufman, A. R. Saltiel, and M. Karin. 2018. ER stress drives lipogenesis and steatohepatitis via caspase-2 activation of S1P. Cell 175:133-145.

Liu, J., X. Jin, C. H. Yu, S. H. Chen, W. P. Li, and Y. M. Li. 2010 Endoplasmic reticulum stress involved in the course of lipogenesis in fatty acids-induced hepatic steatosis. J. Gastroenterol. Hepatol. 25:613-618. https://doi.org/10.1111/j.1440-1746.2009.06086.x.

Loor, J. J., M. Bionaz, and J. K. Drackley. 2013. Systems physiology in dairy cattle: Nutritional genomics and beyond. Annu. Rev. Anim. Biosci. 1:365-392. https://doi.org/10.1146/annurev-animal -031412-103728.

Loor, J. J., R. E. Everts, M. Bionaz, H. M. Dann, D. E. Morin, R. Oliveira, S. L. Rodriguez-Zas, J. K. Drackley, and H. A. Lewin. 2007. Nutrition-induced ketosis alters metabolic and signaling gene 
networks in liver of periparturient dairy cows. Physiol. Genomics 32:105-116. https://doi.org/10.1152/physiolgenomics.00188.2007.

McAndrew, D., D. M. Grice, A. A. Peters, F. M. Davis, T. Stewart, M. Rice, C. E. Smart, M. A. Brown, P. A. Kenny, S. J. RobertsThomson, and G. R. Monteith. 2011. ORAI1-mediated calcium influx in lactation and in breast cancer. Mol. Cancer Ther. 10:448 460. https://doi.org/10.1158/1535-7163.MCT-10-0923.

Oetzel, G. R. 2004. Monitoring and testing dairy herds for metabolic disease. Vet. Clin. North Am. Food Anim. Pract. 20:651-674. https://doi.org/10.1016/j.cvfa.2004.06.006.

Osorio, J. S., P. Ji, J. K. Drackley, D. Luchini, and J. J. Loor. 2013. Supplemental Smartamine M or MetaSmart during the transition period benefits postpartal cow performance and blood neutrophil function. J. Dairy Sci. 96:6248-6263. https://doi.org/10.3168/jds $.2012-5790$

Osorio, J. S., J. Lohakare, and M. Bionaz. 2016. Biosynthesis of milk fat, protein, and lactose: Roles of transcriptional and posttranscriptional regulation. Physiol. Genomics 48:231-256. https://doi .org/10.1152/physiolgenomics.00016.2015.

Ringseis, R., D. K. Gessner, and K. Eder. 2015. Molecular insights into the mechanisms of liver-associated diseases in early-lactating dairy cows: Hypothetical role of endoplasmic reticulum stress. J. Anim. Physiol. Anim. Nutr. (Berl.) 99:626-645. https://doi.org/ 10.1111/jpn.12263.

Schultz, L. H. 1968. Ketosis in dairy cattle. J. Dairy Sci. 51:1133-1140. https://doi.org/10.3168/jds.S0022-0302(68)87141-3.

Silvestre, A. M., F. Petim-Batista, and J. Colaco. 2006. The accuracy of seven mathematical functions in modeling dairy cattle lactation curves based on test-day records from varying sample schemes. J. Dairy Sci. 89:1813-1821. https://doi.org/10.3168/jds.S0022 -0302(06) 72250-0.

Soboloff, J., B. S. Rothberg, M. Madesh, and D. L. Gill. 2012. STIM proteins: Dynamic calcium signal transducers. Nat. Rev. Mol. Cell Biol. 13:549-565. https://doi.org/10.1038/nrm3414.

Sun, X., Y. Wang, J. J. Loor, R. Bucktrout, X. Shu, H. Jia, J. Dong, R. Zuo, G. Liu, X. Li, and X. Li. 2019. High expression of cell death-inducing DFFA-like effector a (CIDEA) promotes milk fat content in dairy cows with clinical ketosis. J. Dairy Sci. 102:16821692. https://doi.org/10.3168/jds.2018-15439.

Torrens, J. M., J. M. Orellana-Gavalda, M. Palou, J. Sanchez, L. Herrero, C. Pico, D. Serra, and A. Palou. 2014. Enhancing hepatic fatty acid oxidation as a strategy for reversing metabolic disorders programmed by maternal undernutrition during gestation. Cell Physiol. Biochem. 33:1498-1515.

Wilmink, J. B. M. 1987. Adjustment of test-day milk, fat and protein yield for age, season and stage of lactation. Livest. Prod. Sci. 16:335-348. https://doi.org/10.1016/0301-6226(87)90003-0.

Yu, L., B. Jiang, Z. Chen, X. Wang, D. Shang, X. Zhang, Y. Sun, J. Yang, and Y. Ji. 2018. Cytisine induces endoplasmic reticulum stress caused by calcium overload in HepG2 cells. Oncol. Rep. 39:1475-1484. https://doi.org/10.3892/or.2018.6200.

Zhang, B., M. Li, Y. Zou, H. Guo, B. Zhang, C. Xia, H. Zhang, W. Yang, and C. Xu. 2019. NFkappaB/Orai1 facilitates endoplasmic reticulum stress by oxidative stress in the pathogenesis of nonalcoholic fatty liver disease. Front. Cell Dev. Biol. 7:202. https:// doi.org/10.3389/fcell.2019.00202.

Zhang, B., W. Yang, Y. Zou, M. Li, H. Guo, H. Zhang, C. Xia, and C. Xu. 2018. NEFA-sensitive Orail expression in regulation of de novo lipogenesis. Cell Physiol. Biochem. 47:1310-1317.

Zhang, M., S. Zhang, Q. Hui, L. Lei, X. Du, W. Gao, R. Zhang, G. Liu, X. Li, and X. Li. 2015. Beta-hydroxybutyrate facilitates fatty acids synthesis mediated by sterol regulatory element-binding protein1 in bovine mammary epithelial cells. Cell Physiol. Biochem. $37: 2115-2124$

Zhu, M., S. Zhou, Z. Huang, J. Wen, and H. Li. 2016. $\mathrm{Ca}^{2+}$-dependent endoplasmic reticulum stress regulates mechanical stress-mediated cartilage thinning. J. Dent. Res. 95:889-896. https://doi.org/10 $.1177 / 0022034516640206$.

\section{ORCIDS}

Bingbing Zhang (ํ) https://orcid.org/0000-0002-1869-9652

Ming Li ๑ https://orcid.org/0000-0001-8837-9964

Wei Yang $\odot$ https://orcid.org/0000-0003-3440-2190

Juan J. Loor @ https://orcid.org/0000-0003-1586-4365

Shuang Wang $\odot$ https://orcid.org/0000-0001-7097-2858

Yingying Zhao •

Han Guo (ㄴ) https://orcid.org/0000-0002-6386-4100

Xinru Ma ๑ https://orcid.org/0000-0003-2392-8015

Chuang Xu ৫ https://orcid.org/0000-0002-0377-1439 